\title{
Landslide risk assessment by using a new combination model based on a fuzzy inference system method
}

\author{
S. Reza Azimi ${ }^{1}$, Hamid Nikraz ${ }^{2}$, Abdolreza Yazdani-Chamzini ${ }^{3}$ \\ 1,2 Department of Civil Engineering, Faculty of Science and Engineering, Curtin University \\ ${ }^{3}$ Young Researchers and Elite Club, South Tehran Branch, Islamic Azad University, Tehran, Iran; \\ Email: $\underline{\text { sr_azimi@yahoo.com }}{ }^{1} ; \underline{\text { h.nikraz@curtin.edu.au }}{ }^{2} ; \underline{\text { abdalrezaych@gmail.com }}^{3}$ (corresponding author)
}

\begin{abstract}
Landslides are one of the most dangerous phenomena that pose widespread damage to property and human lives. Over the recent decades, a large number of models have been developed for landslide risk assessment to prevent the natural hazards. These models provide a systematic approach to assess the risk value of a typical landslide. However, often models only utilize the numerical data to formulate a problem of landslide risk assessment and neglect the valuable information provided by experts' opinion. This leads to an inherent uncertainty in the process of modelling. On the other hand, fuzzy inference systems are among the most powerful techniques in handling the inherent uncertainty. This paper develops a powerful model based on fuzzy inference system that uses both numerical data and subjective information to formulate the landslide risk more reliable and accurate. The results show that the proposed model is capable of assessing the landslide risk index. Likewise, the performance of the proposed model is better in comparison with that of the conventional techniques.
\end{abstract}

Keywords: fuzzy inference system, landslide risk assessment, Combination model, Comparison analysis 


\section{Introduction}

Landslide is one of the most frequent geohazards in the mountainous regions of the world that globally threatens property and lives. This phenomenon is defined as the movement of soil and rock down slope under the influence of gravity (Juventine, 2012). Landslides may lead to serious damages including psychological, environmental, social, and economical losses.

Landslides have a high potential to detrimentally affect human life. Based on the statistics published by the International Federation of Red Cross and Red Crescent (IFRC), 19 landslides are reported in 2015. These 19 landslides caused 1000 deaths worldwide influencing 50 thousand people and an estimated loss of 8 millions of US dollars. Landslides account for 17 percent of the fatalities from natural hazards (Kjekstad \& Highland, 2009). Dilley et al (2005) stated that an area corresponding 2.5 percent of the world's land surface is prone to landslides, affecting 5 percent of world population. In order to show the key importance of landslide hazard assessment, Table 1 presents the global significance of landslide impact.

Table 1. Total annual losses due to landslides in some countries (Klose, 2015)

\begin{tabular}{c|c|c}
\hline Country & Total annual loss (USD billion) & Loss as percentage of GDP \\
\hline USA & $2.1-4.3$ & $0.01-0.03$ \\
\hline Japan & $>3.0$ & $>0.06$ \\
\hline Italy & 3.9 & 0.19 \\
\hline India & 2.0 & 0.11 \\
\hline China & $>1.0$ & 0.01 \\
\hline Germany & 0.3 & 0.01 \\
\hline
\end{tabular}

Hence, there is a necessity to examine the landslide hazards as the potential threats to society and to provide a powerful model for making a proper decision in order to reduce the losses in the future disasters. On the other hand, such models help authorities to better cope with hazards by knowing how big landslides will be. However, a landslide risk assessment model plays an increasingly key role in 
decrease of landslide hazards. Several reasons can lead to an increase in the use of landslide risk assessment: (i) there is a substantial vagueness connected to the ground and underground conditions, (ii) an excellent risk model helps authorities to rank the landslides from the most dangerous to the least dangerous in a descending order in order to concentrate the financial resources on more dangerous landslides by rational strategies, and (ii) a risk based model helps managers to extract how each component can influence the level of the risk and conduct a sensitivity analysis for selection of some preventive measures. A landslide risk assessment approach provides a framework that reflects the threats and costs resulted from landslides. This procedure effectively helps authorities to better manage landslide hazards and dramatically reduces the costs and threats arisen from landslide events.

Therefore, a substantial progress in the development of landslide risk assessment during the recent century across the world has been observable. Different kinds of models are developed to formulate the behavior of a landslide hazard. Reger (1979) employed discriminant analysis to statistically distinguish failed and unfailed embankments. An intelligent model based on artificial neural network was developed to assess the landslide risk (Ermini et al, 2005; Choi et al, 2010; Tsangaratos \& Benardos, 2014). A combination model based on logistic regression analysis and geographic information system was applied for landslide risk assessment (Bai et al, 2015; Pradhan \& Abdulwahid, 2017). Santacana et al (2003) used multi-variate statistical analysis for landslide risk assessment. Leonardi et al (2016) employed a fuzzy logic model for landslide susceptibility assessment of Reggio Calabria territory. Sarkar et al (2013) developed a model based on information value method for landslide susceptibility assessment in parts of the Darjeeling Himalayas. Shit et al (2016) utilized weighted overlay model for the potential landslide susceptibility mapping. Anbalagan et al (2015) applied frequency ratio approach to investigate landslide hazard. A landslide susceptibility mapping by using the weights of evidence model is proposed by Pradhan et al (2010). A bivariate statistical 
analysis for landslide susceptibility assessment is proposed by Raman and Punia (2012). They used a nine-layer process to model the landslide susceptibility zones. A procedure based on the statistical approach for landslide risk assessment is developed by Remondo et al (2005). A general framework for probabilistic landslide hazard analysis is presented by Lari et al (2014).

However, uncertainty is an inevitable part of a landslide risk assessment procedure resulting from data uncertainty, including incomplete data or measurement errors (systematic and random), and environmental uncertainty, comprising imprecise predictions of future conditions (Lee and Jones, 2004). As well as, some uncertainties such as socio-economic changes may accumulate in the future and lead to a non-probabilistic pattern. Although some researchers demonstrated that the models developed based on a probability density function are useful and effective (Vu-Bac et al, 2016, Hamdia et al, 2017), Shroder and Davies (2015) showed that a risk analysis process by using the probabilistic approach requires a large number of data. They demonstrated with a sample size of 100 , the error is approximately $\pm 10 \%$; whereas, with a sample size of 10 , the error is about $\pm 40 \%$; and, as a result, with a sample size of 2 , the error is $\pm 95 \%$. An important difficulty with probabilistic analysis is related to the limited number of landslide events occurring in a specific area because some preventive measures will be accomplished by society to mitigate potential hazards. Therefore, it can be lead to an inefficient probability distribution. Based on the statistics issued by Shroder and Davies (2015) for events that happen with a frequency of less than 5 times during a specific period, a probabilistic analysis involves intrinsic and large imprecision. From technical point of view, researchers are mostly inclined to view landslides as a predictable event that irregularly takes place. Therefore, it is inappropriate to make an attempt to create the probability distributions or models (Lee and Jones, 2004). 
To face with such limitations, one logical approach is to extract some complementary information from expert's knowledge. An efficient strategy is the use of more reliable and realistic techniques such as fuzzy inference system models.

Likewise, in many situations, it is valuable to use both subjective appraisal and factual data to accurately evaluate the level of hazards for the purpose of making a correct decision with limited resources. This can lead to a 90 percent reduction in losses of landslides by applying all feasible measures (Alfors et al, 1973).

The main objective of this paper is to develop a landslide risk assessment model by using numerical data and subjective information in form of a fuzzy inference system model to accurately investigate the potential areas of the future hazards. Developing a combination model that is capable of formulating a complex problem by using both objective and subjective information can increase the level of model precision for making a better decision. The proposed model can help authority to (i) identify the areas exposed to landslide hazards, (ii) develop some preventive measures, and (iii) prevent the resources from wasting by concentrating on the areas with high potential for damage.

\section{The mechanics of landslide}

Landslides are among the many natural disasters causing massive destructions and loss of lives across the globe (Davies, 2015). The main reasons of landslides are pertaining to the instability in slopes. A landslide may accrue because of some landslide causes and triggers. There is a significant difference in the concepts of causes and triggers. The first one is the reasons of occurring a landslide event including geological factors, morphological factors, physical factors and factors associated with human activity. Whereas, the last one is a component that initiates the landslide event, including rainfalls, earthquakes, and volcanic activities. 
The mechanic of landslides are usually differentiated by the nature of its movement and the earth material involved (Bobrowsky \& Highland, 2013), comprising slide (a downslope movement of a soil or rock mass occurring on surfaces of rupture or on relatively thin zones of intense shear strain), topple (movement of huge masses of rock, debris, and earth from a slope), fall (sudden movements of loads of soil, debris, and rock that break away from slopes), and flow (a spatially continuous movement in which the surfaces of shear are short-lived, closely spaced, and usually not preserved).

\section{Fuzzy inference system}

\subsection{Fuzzy set}

There are a close relationship between complexity and certainty, so that; increasing the complexity lead to decrease the certainty.

Fuzzy theory enables decision makers to simply formulate a sophisticated problem by using the linguistic terms instead of precise and strict values. Fuzzy logic provides a methodology for computing directly with words (Zadeh, 1996). The principal concept of a typical fuzzy set can be defined as an extension of the classical one. A fuzzy set allows elements to have a smooth boundary. This method, first developed by Zadeh (1965), is capable of handling the uncertainty imposed by the problem under consideration. This technique employs the membership functions, the cornerstone of fuzzy concepts, to handle the uncertainty involved in the process of formulation. This theory can describe the membership of an element with some partial degree. Whereas, a classical set only allows to have a sharp boundary. A fuzzy number belong to the closed interval 0 and 1 , where 1 addresses full membership and 0 expresses non-membership. Whereas, crisp sets only allow 0 or 1.

\subsection{Fuzzy inference system}

Many real world problems cope with the inherent uncertainty involved in the process of data gathering and formulating. On the other hand, the traditional techniques are disable to handle the uncertainty 
and find the best solution. Therefore, fuzzy logic is developed by Zadeh (1965) to model a problem under uncertainty environment. The fuzzy logic provides a scientific basis for translating the verbal expressions into the corresponding numerical values. The procedure of modelling an input fuzzy set map to an output fuzzy set by employing the fuzzy logic is fuzzy inference system (Razani et al, 2013). The fuzzy inference system (FIS) has the ability to extrapolate the relation between a series of input to an output with the help of fuzzy logic (Hamdia et al. 2015).

This technique is capable of integrating imprecision and vagueness into the models (Kaya and Çınar, 2008). The fuzzy inference system is employed by an enormous number of researchers. A fuzzy model, contrary to other black-box approaches such as artificial neural network method, is easily understandable, interpretative, and analyzable. A typical fuzzy inference system contains four main parts. The most important part of a fuzzy system is inference unit, in which the facts resulted from the fuzzification process are combined with the knowledge base. In the following sub-sections, each part of a fuzzy system is clearly explained. An FIS model is capable of recognizing a complex nonlinear structure involved in data as a combination of multiple simple input-output relations.

\subsubsection{Fuzzification process}

In the first step, a fuzzification process is conducted to convert the crisp inputs into degrees of the match with linguistic variables. The membership function (MF) is used to associate a grade to each linguistic term. It means that an input vector, including crisp values, uses the MFs to transfer the values to linguistic terms. Different shapes of linear and nonlinear MFs have been developed to formulate the complex structures involved in dataset (Yazdani-Chamzini, 2014). The type of the MF depends on the expert's knowledge and the problem under consideration. 


\subsubsection{Knowledge base}

The knowledge base is constructed from two basic parts, comprising the rule base and data base (Yazdani-Chamzini et al, 2013). The rule base is formed by a set of the fuzzy if-then rules. The data base defines the MFs of the fuzzy sets employed for the fuzzy rule generation. An if-then rule is resulted from numerical data, engineering knowledge, and subjective information. The if-then rule defines the relationships between input-output variables. Generally, a fuzzy conditional rule comprises two main parts, including a premise (antecedent) and a consequent (conclusion) part (Razani et al, 2013).

\subsubsection{Inference unit (fuzzy inference engine)}

A fuzzy inference system uses human knowledge to describe the relationship between input-output variables in the form of If-Then rules, where a typical If-Then rule contains of antecedent and consequent parts (Jamshidi et al, 2013). The former part shows how to partition an input space. The later part reflects the control value of a rule space. The fuzzy system models based on the expression of the consequent part are classified into three main algorithms (Yazdani-Chamzini et al, 2013): Mamdani, Takagi-Sugeno-Kang (TSK), and Tsukamoto fuzzy models.

A Mamdani fuzzy model employs a membership function to define a fuzzy value in the consequence part. However, the Mamdani model helps experts to simply reflect their knowledge in the rule definition. The Mamdani models are suitable for knowledge processing expert systems rather than for control expert systems (Takagi, 1997).

In the basic concepts of the TSK models, a fuzzy rule is defined by a function of weighted input variables in the form of a linear structure. It is noted that the TSK models are not limited to a linear function but a nonlinear function of input variables can be extracted by an artificial neural network (ANN) model. In such situations, the transparency of rules is traded off against the model performance. 
Each rule in the TSK model can be defined as a local linear model of the nonlinear process (Kaymak et al, 1997). In the system of a simplified fuzzy model, a fuzzy rule uses constant value to form its consequence part. This model can be defined as a special case of both the TSK and Mamdani algorithms (Takagi, 1997). The Tsukamoto fuzzy model uses a fuzzy set with a monotonically increasing or decreasing membership function to represent the consequent of each fuzzy if-then rule. In this model, the overall output is resulted from computing the weighted average of each rule's output (Grosan \& Abraham, 2011).

\subsubsection{Defuzzification process}

In the final step of the risk assessment fuzzy model, a process of conversion of fuzzy values to their corresponding crisp ones is conducted to the model output be applied for further evaluations. Therefore, the results of the landslide risk assessment model are transferred into crisp values by using a defuzzification process. Although different defuzzification algorithms are developed, the centroid of area (COA) is the most widely applied method (Yazdani-Chamzini, 2014). The most advantage of the COA method is to employ all activated membership functions of the conclusions (Daftaribesheli et al, 2011).

\section{The proposed combination model}

Landslide risk assessment is an essential process to (i) create risk reduction scenarios based on resource management, (ii) conduct a cost-benefit analysis of preventive measures for landslide prone zones, (iii) construct a systematic mechanism for risk reduction through risk management strategies

such as risk sharing and insurance, (iv) control and manage the financial and human resources by allocating the resources to corresponding consumptions, and (v) conduct a sensitivity analysis in order to understand the effect of each parameter on risk value for the most concentration on the most effective parameter. Therefore, the proposed model provides a strategic approach to identify where 
landslides have enormous potential for occurring and how big they will be. The proposed model for the landslide risk assessment is a three-phase process. The first phase employs the Mamdani algorithm to assess the consequence index based on the qualitative information extracted from expert knowledge. The second phase uses a TSK algorithm to calculate the vulnerability index based on the geotechnical properties of soil, in which the numerical data is available. The last phase computes the risk index based on the data resulted from the two previous phases and the information extracted form expert knowledge. The unique feature of the proposed model is to integrate the factual data and subjective information in the form of a powerful technique for landslide risk assessment. This leads to a more accurate and reliable assessment of the risks associated with natural hazards. The first phase focuses on the overall consequence of a landslide event and is defined as the consequence index. The consequence index is assessed by the four sub-criteria, including personal, financial, environmental, and technical impacts. This phase employs a Mamdani fuzzy system under MATLAB environment to assess the consequence index by using the four sub-criteria. This index is resulted from the overall potential consequences of a landslide event. The second phase provides a systematic framework to assess the vulnerability index based on five sub-criteria, including soil properties, including soil depth, slope angle, angle of internal friction, cohesion, and specific yield of soil. This phase evaluates the potential for a landslide event and is defined as an internal factor pertaining to the soil. This factor is different from the likelihood of landslide that is defined as an external factor pertaining to the environment. The vulnerability index is calculated by the TSK fuzzy model established in Matlab software. The last phase calculates the overall risk index to make a proper decision based on the level of the risk. In this phase, the risk index is derived from a combination of the consequence index (resulted from the first phase), the vulnerability index (resulted from the second phase), and the likelihood of a landslide event (resulted from experts' opinion). This phase also uses a Mamdani fuzzy 
system by using MATLAB software to assess the level of the risk. After calculating the risk index, the values are prioritized in descending order. Next, the susceptible sites for landslide are highlighted to be improved by appropriate strategies.

\section{Case study}

An experimental research was conducted to demonstrate the performance of the proposed model. For achieving the aim, soil samples were collected from an area of Gaskell Ave, Ellenbrook, Western Australia. A standard collection (AS 1141.3.1-2012) procedure was followed, which involved establishment of a platform where the collected soil was placed and then the soil was mixed thoroughly several times to obtain a representative well-mixed sample. Some soil physical properties for landslide risk assessment are presented in Table 2.

Table 2. Soil physical properties (Azimi, 2016; Azimi \& Nikraz, 2017)

\begin{tabular}{c|c|c}
\hline \multirow{2}{*}{ Dry Density } & Maximum & $1.86 \mathrm{t} / \mathrm{m} 3$ \\
\cline { 2 - 3 } & Minimum & $1.56 \mathrm{t} / \mathrm{m} 3$ \\
\hline Sodium Sulphate Soundness & & $0.1 \%$ \\
\hline Light Particles & & $<1$ \\
\hline Clay and Fine Silt & & $3 \%$ \\
\hline Fineness Modulus & 1.9 \\
\hline Material Finer than 2 micron & & $0.2 \%$ \\
\hline Acid Soluble Salts & $\mathrm{Cl}$ & $<0.01 \%$ \\
\cline { 2 - 3 } & $\mathrm{SO}_{4}$ & $0.03 \%$ \\
\hline
\end{tabular}

\section{Construction of fuzzy inference system}

The data gathering is the first stage of the risk assessment process where the raw data is collected and pre-processing analysis (i.e. fuzzification and aggregation process) is required. The raw data includes two main categories comprising numerical data and subjective information. The former, a quantitative value, is calculated by using a mathematical, experimental, technical, and analytical procedure; whereas, the latter is a qualitative evaluation made by a professional expert team, comprising thirteen professional and academic experts with an average age of 43.38 years (background information on experts is presented in Table 3). 
Table 3. Background information on experts

\begin{tabular}{c|c|c}
\hline \multirow{2}{*}{ Category } & Classification & No. \\
\hline \multirow{4}{*}{ Education background } & Civil engineering & 5 \\
\cline { 2 - 3 } & Mining engineering & 3 \\
\cline { 2 - 3 } & Geotechnical engineering & 3 \\
\cline { 2 - 3 } & Mechanical engineering & 2 \\
\hline \multirow{3}{*}{ Education level } & Bachelor & 2 \\
\cline { 2 - 3 } & Master & 5 \\
\cline { 2 - 3 } & PhD & 11 \\
\hline \multirow{2}{*}{ Sex } & Male & 2 \\
\hline \multirow{2}{*}{ Age } & Female & 2 \\
\hline & $30-40$ & 2 \\
\hline
\end{tabular}

In this study, the vulnerability index is obtained by numerical data and the consequence and risk indices are calculated by experts' knowledge.

After data gathering, the proposed model is implemented. The proposed model comprises three main phases. The first phase includes four inputs for measuring the consequence index. The second phase contains five inputs for computing the vulnerability index. Then, the outputs of the two aforementioned phases are redefined by fuzzy theory and combined with the likelihood to calculate the risk index. Therefore, the last level calculates the risk index based on the consequence, vulnerability, and likelihood indices. In the following sub-sections, each phase is comprehensively illustrated and the results are clearly described.

\subsection{Fuzzy model for the consequence index}

Firstly, a model based on fuzzy inference system is established to calculate the consequence value. To achieving the aim, the fuzzy model comprises four inputs, including personal, financial, environmental, and technical impacts, and one output (i.e. consequence index). In this study, based on the experts' opinion, 625 fuzzy if-then rules are firstly generated. However, some of the rules have an 
insignificant change in the model output and can be ignored to reduce the complexity of fuzzy systems. This strategy is applied by a lot of research work to only select a set of important fuzzy rules. Wen and Wang (1999) showed the removal of redundant or less important rules from the rule base can result in a fuzzy model with better generalizing ability. Therefore, by using rule reduction strategy, 70 rules are known as effective rules for constructing the rule base. The output of the fuzzy model for the consequence index is presented in Table 4.

Table 4. The features of the fuzzy model established for the consequence index

\begin{tabular}{|c|c|}
\hline Name & CONSEQUENCE \\
\hline Type & mamdani \\
\hline Inputs/Outputs & {$\left[\begin{array}{ll}4 & 1\end{array}\right]$} \\
\hline NumInputMFs & {$\left[\begin{array}{llll}5 & 5 & 5 & 5\end{array}\right]$} \\
\hline NumOutputMFs & 5 \\
\hline NumRules & 70 \\
\hline AndMethod & $\min$ \\
\hline OrMethod & $\max$ \\
\hline ImpMethod & $\min$ \\
\hline AggMethod & $\operatorname{Max}$ \\
\hline DefuzzMethod & Centroid \\
\hline \multirow{4}{*}{ InLabels } & Personal \\
\hline & Financial \\
\hline & Environmental \\
\hline & Technical \\
\hline OutLabels & Consequences \\
\hline \multirow{4}{*}{ InRange } & [1 5] \\
\hline & [1 5] \\
\hline & [1 5] \\
\hline & [1 5] \\
\hline OutRange & {$\left[\begin{array}{ll}0 & 1\end{array}\right]$} \\
\hline
\end{tabular}

The control surface is a sensitivity analysis tool to evaluate the interdependency of input and output components. The interdependency of two input parameters, comprising personal and financial impacts, and the consequence index is shown in Fig. 1. From the figure, it can be obvious that there is a significant interdependency of consequences on personal and financial impacts. 


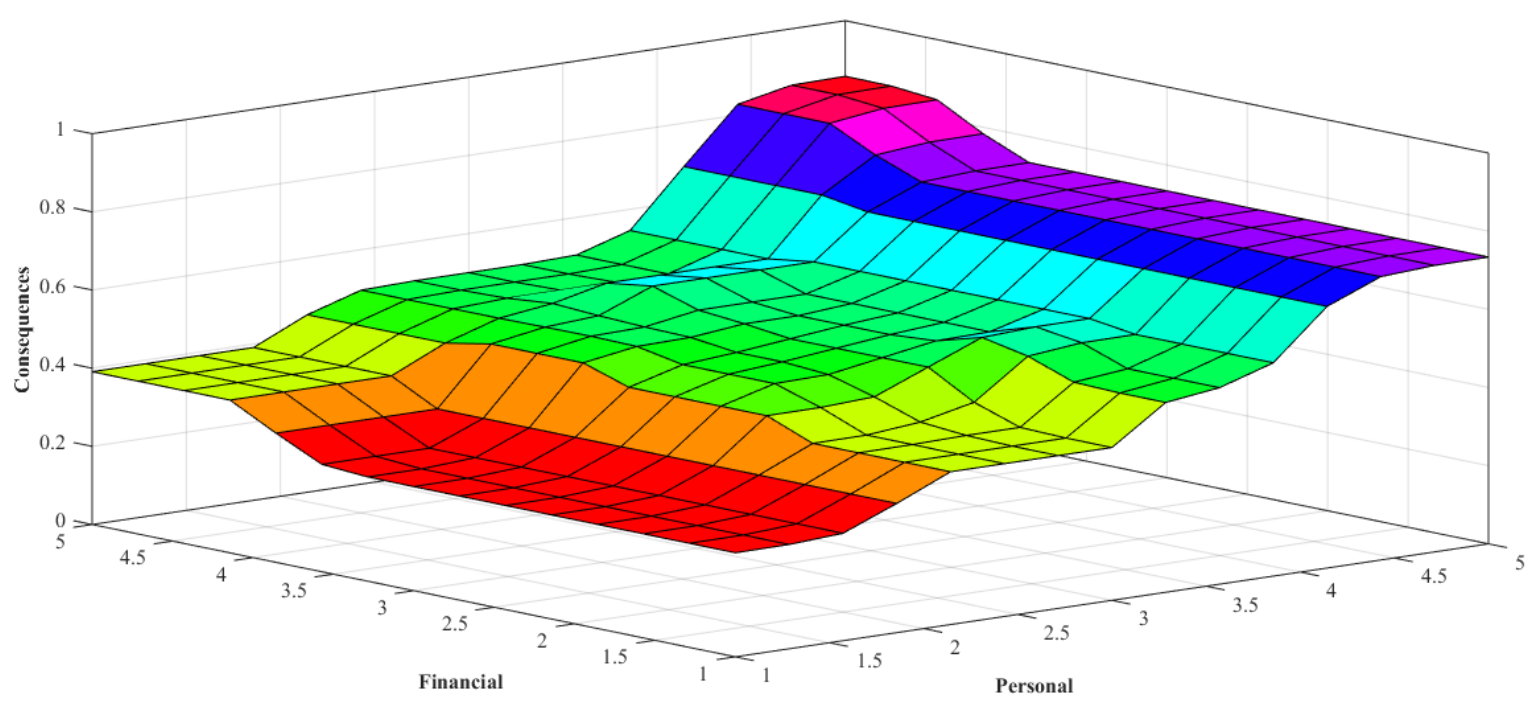

Fig. 1. Control surface of consequences on financial and personal impacts

\subsection{Fuzzy model for the vulnerability index}

The vulnerability index expresses the degree of damage based on soil properties. The fuzzy model for obtaining the vulnerability value includes five effective components, including soil depth (depth), slope angle (angle), angle of internal friction (friction), cohesion, and specific yield of soil (specific). This model uses the framework of the TSK algorithm to generate the if-then rules. For achieving the aim, fifty data series obtained from experimental data (Mandal and Maiti, 2015) are employed for rule generation as listed in Table 5. 
Table 5. Basic statistical descriptions on data set

\begin{tabular}{l|c|c|c|c|c|c}
\hline & Depth & Angle $^{*}$ & Friction $^{* *}$ & Cohesion & Specific & Vulnerability $^{* * *}$ \\
\hline Unit & $\mathrm{m}$ & - & - & $\mathrm{kg} / \mathrm{cm}^{2}$ & $\mathrm{KN} / \mathrm{m}^{3}$ & - \\
\hline Minimum & 0.450 & 0.325 & 0.391 & 0.010 & 1.790 & 0.282 \\
\hline Maximum & 3.750 & 0.649 & 0.974 & 0.910 & 2.580 & 4.958 \\
\hline Median & 1.400 & 0.466 & 0.743 & 0.270 & 2.045 & 1.296 \\
\hline Mean & 1.582 & 0.468 & 0.710 & 0.339 & 2.103 & 1.644 \\
\hline Std. Dev. & 0.806 & 0.081 & 0.173 & 0.273 & 0.193 & 1.142 \\
\hline Skewness & 1.080 & 0.262 & -0.368 & 0.526 & 0.857 & 1.253 \\
\hline Kurtosis & 0.547 & -0.696 & -0.958 & -1.018 & 0.020 & 1.155 \\
\hline Sum & 79.120 & 23.407 & 35.477 & 16.970 & 105.130 & 82.195 \\
\hline Type & Input & Input & Input & Input & Input & Output \\
\hline
\end{tabular}

* Soil angle is calculated by its cosine.

** Angle of internal friction is obtained by its tangent.

*** Vulnerability is measured by the reverse of safety factor.

After training the fuzzy system by using subtractive clustering method, 25 if-then rule are generated.

The output of the fuzzy model established for the vulnerability index is shown in Table 6 .

Table 6. The features of the fuzzy model established for the vulnerability index

\begin{tabular}{c|c}
\hline Name & Vulnerability \\
\hline Type & sugeno \\
\hline Inputs/Outputs & {$[51]$} \\
\hline NumInputMFs & {$[2525252525]$} \\
\hline NumOutputMFs & 25 \\
\hline NumRules & Prod \\
\hline AndMethod & Probor \\
\hline OrMethod & Prod \\
\hline ImpMethod & Sum \\
\hline AggMethod & wtaver \\
\hline DefuzzMethod & Depth \\
\hline \multirow{5}{*}{ InLabels } & Angle \\
\cline { 2 - 2 } & Criction \\
\cline { 2 - 2 } & Cohesion \\
\cline { 2 - 2 } & Specific \\
\cline { 2 - 2 } OutLabels & Vulnerability \\
\hline \multirow{4}{*}{ InRange } & {$[0.453 .75]$} \\
\cline { 2 - 2 } & {$[0.22691 .169]$} \\
\cline { 2 - 2 } & {$[0.31420 .576]$} \\
\cline { 2 - 2 } & {$[0.010 .91]$} \\
\hline OutRange & {$[0.2824 .958]$} \\
\hline
\end{tabular}


The control surface of vulnerability on depth and friction is depicted in Fig. 2.

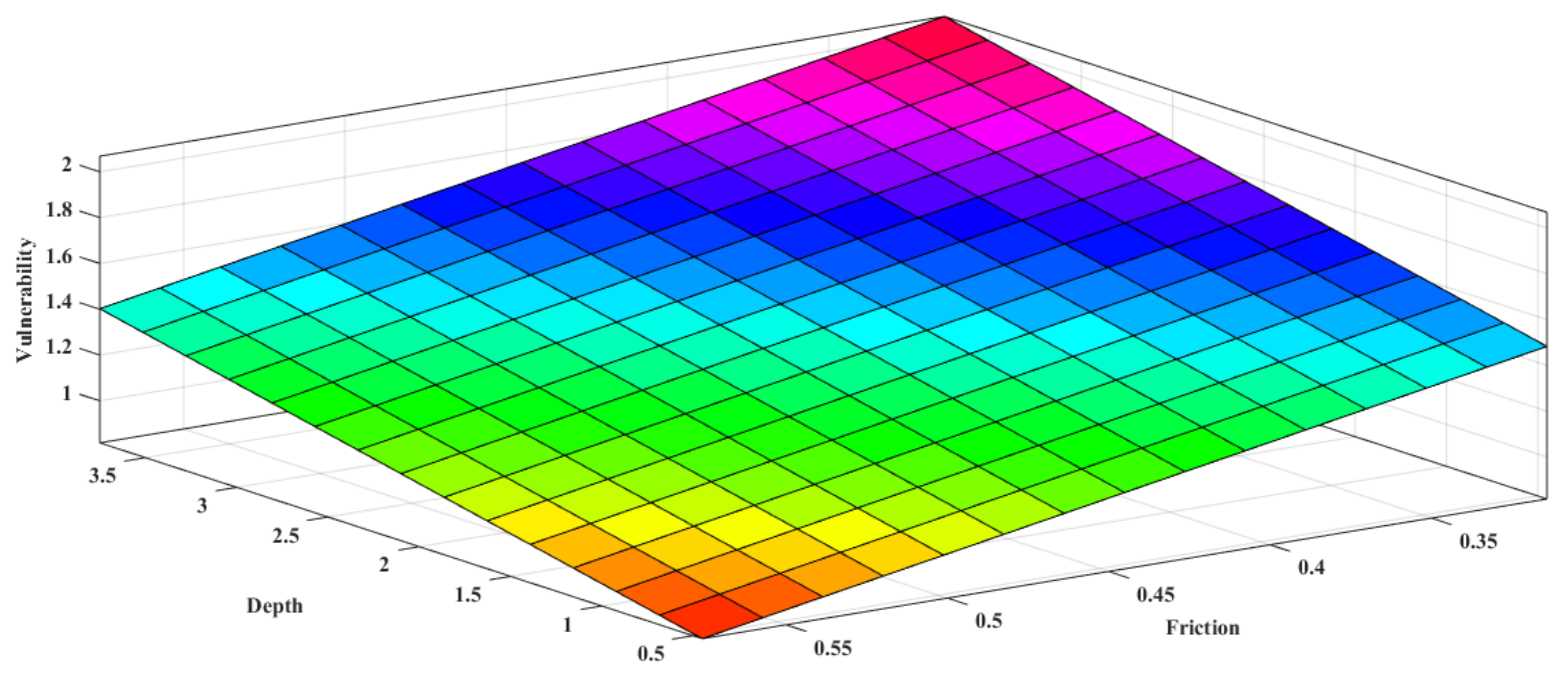

Fig. 2. Control surface of vulnerability on depth and friction

From the figure, it can be seen that there is a linear interdependency among depth, friction, and vulnerability.

\subsection{Final determination of risk index}

The outputs obtained by the consequence and vulnerability indices are evoked by the third fuzzy model to compute the risk index for future analysis. Therefore, the two outputs produced by the consequence and vulnerability indices are combined with the third index (i.e. likelihood of landslide event) generated by experts' opinion to form the three inputs for the fuzzy risk index. Finally, the landslide risk assessment is obtained by using a combination of linguistic variables and fuzzy computations produced by two previous sub-sections. The risk values generated from the proposed model can be allocated for different sites to detect a site with high potential for landslide and provide a base for making a proper decision. The features of the proposed model for risk index is presented in Table 7. 
Table 7. The output of the proposed model for the risk index

\begin{tabular}{|c|c|}
\hline Name & Risk \\
\hline Type & mamdani \\
\hline Inputs/Outputs & {$\left[\begin{array}{ll}3 & 1\end{array}\right]$} \\
\hline NumInputMFs & {$\left[\begin{array}{llll}5 & 5 & 5 & 5\end{array}\right]$} \\
\hline NumOutputMFs & 5 \\
\hline NumRules & 38 \\
\hline AndMethod & $\min$ \\
\hline OrMethod & $\max$ \\
\hline ImpMethod & $\min$ \\
\hline AggMethod & $\max$ \\
\hline DefuzzMethod & Centroid \\
\hline \multirow{3}{*}{ InLabels } & Consequences \\
\hline & Vulnerability \\
\hline & Likelihood \\
\hline OutLabels & Risk \\
\hline \multirow{3}{*}{ InRange } & {$\left[\begin{array}{ll}0 & 1\end{array}\right]$} \\
\hline & {$\left[\begin{array}{ll}0 & 5\end{array}\right]$} \\
\hline & {$\left[\begin{array}{ll}1 & 5\end{array}\right]$} \\
\hline OutRange & {$\left[\begin{array}{ll}0 & 1\end{array}\right]$} \\
\hline
\end{tabular}

From the results, it can be obvious that 38 rules are generated by experts in the form of rule reduction system to efficiently formulate the relationships between input and output variables. Control surface of risk on consequence and vulnerability indices is shown in Fig. 3.

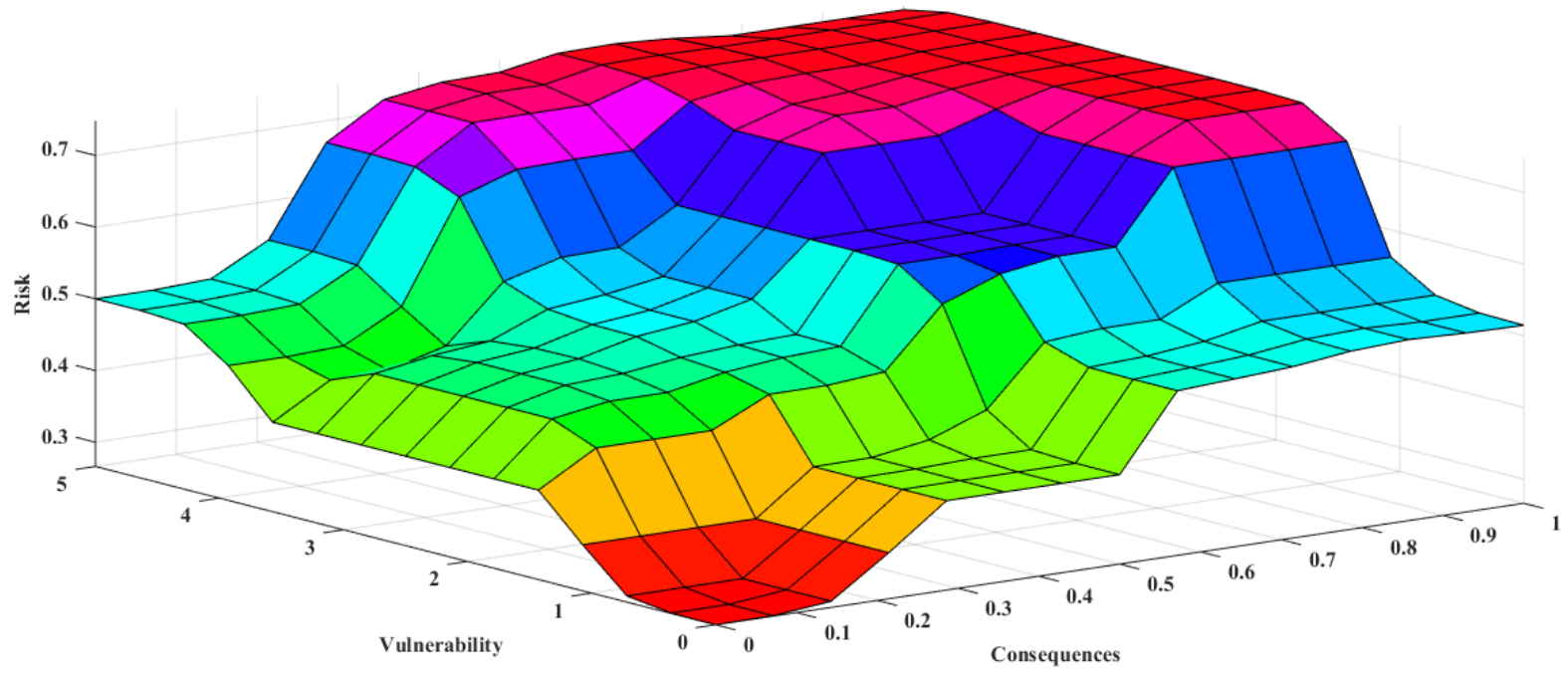

Fig. 3. Control surface of risk on vulnerability and consequences 


\subsection{Validation of the proposed model}

To demonstrate the potential of the model for the landslide risk assessment, the geotechnical field data are gathered from an area of Gaskell Ave, Ellenbrook, Western Australia as given in Table 8.

Table 8. Geotechnical input data

\begin{tabular}{c|c|c|c|c|c}
\hline Sample & Depth & Angle & Friction & Cohesion & Specific \\
\hline 1 & 1.0 & 0.8756 & 0.5533 & 3 & 1.79 \\
\hline 2 & 1.0 & 0.8866 & 0.5233 & 14 & 1.79 \\
\hline 3 & 1.5 & 0.889 & 0.5167 & 17 & 1.79 \\
\hline 4 & 1.5 & 0.890 & 0.5133 & 19 & 1.83 \\
\hline 5 & 1.5 & 0.8907 & 0.5117 & 20 & 1.84 \\
\hline
\end{tabular}

In order to validation of proposed model, the conventional model based on the approach presented by

Guettouche (2013) is conducted as given in Table 9.

Table 9. The required input data of the conventional model

\begin{tabular}{c|c|c|c|c}
\hline Crisp rating & Consequences & Vulnerability & Likelihood & Risk \\
\hline 1 & Negligible & Not vulnerable & Negligible & Negligible \\
\hline 2 & Low & Low & Low & Low \\
\hline 3 & Medium & Medium & Medium & Medium \\
\hline 4 & High & High & High & High \\
\hline 5 & Very high & Very high & Very high & Very high \\
\hline
\end{tabular}

The required input data of the area for the calculation of the conventional and proposed models are presented in Table 10.

Table 10. The results of the models

\begin{tabular}{|c|c|c|c|c|c|c|c|c|c|c|}
\hline & \multicolumn{5}{|c|}{ The Conventional model } & \multicolumn{5}{|c|}{ The proposed model } \\
\hline & 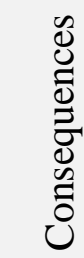 & 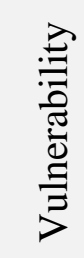 & 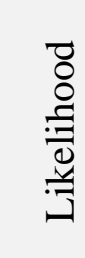 & $\frac{y}{\mathscr{A}}$ & 战 & 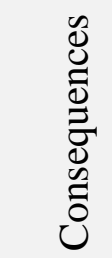 & 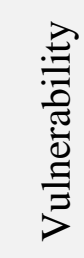 & 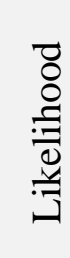 & $\frac{y}{a}$ & 芜 \\
\hline Sample 1 & 1 & 1 & 4 & 2 & 2 & 0.142 & 1.34 & 4 & 0.5 & 2 \\
\hline Sample 2 & 2 & 1 & 2 & 2 & 2 & 0.391 & 1.37 & 2 & 0.435 & 3 \\
\hline Sample 3 & 3 & 2 & 3 & 3 & 1 & 0.609 & 1.52 & 3 & 0.606 & 1 \\
\hline Sample 4 & 1 & 2 & 1 & 2 & 2 & 0.266 & 1.55 & 1 & 0.307 & 4 \\
\hline Sample 5 & 1 & 2 & 2 & 2 & 2 & 0.103 & 1.56 & 2 & 0.274 & 5 \\
\hline
\end{tabular}


The results extracted from the proposed model are more adapted with real world problems. In other words, the proposed model can take into account the relative importance of the components; whereas, the conventional one neglects some components are more/less important. This leads to a fundamental mistake about the outputs; so that, the risk value for sample 1 is equal to samples 2, 4, and 5. Whereas, these samples have different levels of importance. As well as, an error in risk value can lead to a waste of resources. On the other hand, the proposed model has an intrinsic flexibility that can overcome the shortages and limitations of the conventional model and improve the precision of the results.

\section{Conclusion}

Landslide risk assessment provides a systematic procedure to identify the zones with high potential for adverse effects. This procedure helps decision makers to mitigate or eliminate such threats. Therefore, the procedure can be employed to determine vulnerable areas for evaluating different management strategies to make a better decision on the potential hazards. Different researches have been conducted to assess the landslide risk to minimize the adverse effects of landslide hazards. Fuzzy models are among the best techniques in risk assessment. However, for obtaining a more precise model, both factual data and quantitative information should be applied. In this paper, a new model based on fuzzy systems is proposed to formulate the risk level of a landslide. The proposed model uses both numerical data (extracted from experimental analysis and laboratory tests) and quantitative information (extracted from experts' opinion) to accurately assess the risk value for landslides. This can lead to a more accurate result and make a proper decision for preventive measures. The results of the proposed model in comparison with those of the conventional model demonstrate that the fuzzy landslide risk assessment outperforms other techniques. It is suggested that the proposed model be applied for other risk assessment problems to successfully gain from the practical application of the model. 


\section{References}

Alfors, J.T., Burnett, J.L., and Gay, T.E. (1973). Urban geology master plan for California-the nature, magnitude and costs of geologic hazards in California and recommendations for their mitigation: Bulletin 198, California Division of Mines and Geology, Sacramento, California, pp. 112, https://digitalcommons.law.ggu.edu/caldocs_agencies/256

Anbalagan, R., Kumar, R., Lakshmanan, K., Parida, S., and Neethu, S. (2015). "Landslide hazard zonation mapping using frequency ratio and fuzzy logic approach, a case study of Lachung Valley, Sikkim". Geoenvironmental Disasters 2: 6, DOI: 10.1186/s40677-014-0009-y.

Azimi, S.R. (2016). Soil Slope Stability Techniques: A Comprehensive Analysis. A thesis submitted for the Degree of Master of Philosophy (Civil Engineering) Of Curtin University, School of Civil and Mechanical Engineering, Department of Civil Engineering.

Azimi, S.R., and Nikraz, H. (2017). Developing a model based on image processing for soil slope stability assessment. Global journal of engineering science and researches 4(7): 77-89, http://www.gjesr.com/Issues\%20PDF/Archive-2017/July-2017/9.pdf.

Bai, S., Lu, P., and Wang, J. J. (2015). "Landslide susceptibility assessment of the Youfang catchment using logistic regression". Journal of Mountain Science 12(4): 816-827, DOI: 10.1007/s11629014-3171-5.

Bobrowsky, P., and Highland, L. (2013). The Landslide Handbook-a Guide to Understanding Landslides: A Landmark Publication for Landslide Education and Preparedness. In: Sassa K., Rouhban B., Briceño S., McSaveney M., He B. (eds) Landslides: Global Risk Preparedness. Springer, Berlin, Heidelberg.

Choi, J., Oh, H.J., Won, J.S., and Lee, S. (2010). "Validation of an artificial neural network model for landslide susceptibility mapping". Environmental Earth Sciences 60(3): 473-483, DOI: 10.1007/s 12665-009-0188-0.

Daftaribesheli, A., Ataei, M., and Sereshki, F. (2011). "Assessment of rock slope stability using the Fuzzy Slope Mass Rating (FSMR) system”. Applied Soft Computing 11: 4465-4473, DOI: 10.1016/j.asoc.2011.08.032.

Davies, T. (2015). Landslide Hazards, Risks, and Disasters: Introduction. Shroder, J.F. (editor) Hazards and Disasters Series: Landslide Hazards, Risks, and Disasters. Elsevier Inc.

Dilley, M., Chen, R. S., Deichmann, U., Lerner-Lam, A. L., Arnold, M., Agwe, J., Buys, P., Kjevstad, O., Lyon, B., Yetman, G. (2005). Natural disaster hotspots: A global risk analysis. Washington D.C.: The World Bank. 132 pp.

Ermini, L., Catani, F., and Casagli, N. (2005). "Artificial Neural Networks applied to landslide susceptibility assessment”. Geomorphology 66(1-4): 327-343, DOI: 10.1016/j.geomorph.2004.09.025.

Grosan, C., and Abraham, A. (2011). Intelligent Systems: A Modern Approach. Springer-Verlag Berlin Heidelberg.

Guettouche, M.S. (2013). "Modeling and risk assessment of landslides using fuzzy logic. Application on the slopes of the Algerian Tell (Algeria)". Arab J Geosci 6: 3163-3173, DOI: 10.1007/s12517012-0607-5.

Hamdia, K.M., Lahmer, T., Nguyen-Thoi, T., and Rabczuk, T. (2015). "Predicting the fracture toughness of PNCs: A stochastic approach based on ANN and ANFIS". Computational Materials Science 102: 304-313, DOI: 10.1016/j.commatsci.2015.02.045.

Hamdia, K.M., Silani, M., Zhuang, X., He, P., and Rabczuk, T. (2017). "Stochastic analysis of the fracture toughness of polymeric nanoparticle composites using polynomial chaos expansions". International Journal of Fracture 206(2): 215-227, DOI: 10.1007/s10704-017-0210-6. 
Jamshidi, A., Yazdani-Chamzini, A., Yakhchali, S.H., and Khaleghi, S. (2013). "Developing a new fuzzy inference system for pipeline risk assessment". Journal of Loss Prevention in the Process Industries 26: 197-208, DOI: 10.1016/j.jlp.2012.10.010.

Juventine, E.J. (2012). Landslide hazards: household vulnerability, resilience and coping in Bududa district, eastern Uganda. Submitted in partial fulfilment of the requirements for the degree masters in disaster management, University of the Free State.

Kaya I., Kahraman C., and Çebi S. (2012). Computational Intelligence Techniques for Risk Management in Decision Making. In: Lu J., Jain L.C., Zhang G. (eds). Handbook on Decision Making. Intelligent Systems Reference Library, vol 33. Springer, Berlin, Heidelberg

Kaya, İ., and Çınar, D. (2008). "Facility Location Selection Using a Fuzzy Outranking Method". Journal of Multiple-Valued Logic and Soft Computing 14: 251-263, DOI: 10.1142/9789812774118_0052.

Kaymak, U., Babuska, R., Setnes, M., Verbruggen, H.B., and Lemke, H.R.N. (1997). Methods for simplification of fuzzy models. Intelligent hybrid systems: fuzzy logic, neural networks, and genetic algorithms (Edited by Da Ruan). Springer Science+Business Media, LLC.

Kjekstad, O., and Highland, L. (2009). Economic and social impacts of landslides. In K. Sassa, \& P. Canuti (Eds.), Landslides - Disaster Risk Reduction (pp. 573-587). Berlin: Springer.

Klose, M. (2015). Landslide Databases as Tools for Integrated Assessment of Landslide Risk. Doctoral Thesis accepted by the University of Vechta, Germany. Springer International Publishing Switzerland.

Lari, S., Frattini, P., and Crosta, G.B. (2014). "A probabilistic approach for landslide hazard analysis". Engineering Geology 182(A): 3-14, DOI: 10.1016/j.enggeo.2014.07.015.

Lee, E. M., and Jones, D. K. C. (2004). Landslide risk assessment. Thomas Telford Limited.

Leonardi, G., Palamara, R., and Cirianni, F. (2016). "Landslide Susceptibility Mapping Using a Fuzzy Approach”. Procedia Engineering 161: 380-387, DOI: 10.1016/j.proeng.2016.08.578.

Mandal, S., Maiti, R., (2015). Geo-spatial Variability of Physiographic Parameters and Landslide Potentiality (Chapter 2). Semi-quantitative Approaches for Landslide Assessment and Prediction. Springer Science+Business Media Singapore.

Pradhan, B., and Abdulwahid, W.M. (2017). Landslide Risk Assessment Using Multi-hazard Scenario Produced by Logistic Regression and LiDAR-Based DEM. In: Pradhan B. (eds) Laser Scanning Applications in Landslide Assessment. Springer, Cham, pp 253-275.

Pradhan, B., Oh, H.J., and Buchroithner, M. (2010). "Weights of-evidence model applied to landslide susceptibility mapping in a tropical hilly area". Geomatics, Natural Hazards and Risk 1(3): 199223, DOI: 10.1080/19475705.2010.498151.

Raman, R., and Punia, M. (2012). "The application of GIS-based bivariate statistical methods for landslide hazards assessment in the upper Tons river valley, Western Himalaya, India". Georisk: Assessment and Management of Risk for Engineered Systems and Geohazards 6(3): 145-161, DOI: 10.1080/17499518.2011.637504.

Razani, M., Yazdani-Chamzini, A., and Yakhchali, S.H. (2013). "A novel fuzzy inference system for predicting roof fall rate in underground coal mines". Safety Science 55: 26-33, DOI: 10.1016/j.ssci.2012.11.008.

Reger, J. P. (1979). "Discriminant analysis as a possible tool in landslide investigations". Earth Surf. Process. 4: 267-273, DOI: 10.1002/esp.3290040307.

Remondo, J., Bonachea, J., and Cendrero, A. (2005). "A statistical approach to landslide risk modelling at basin scale: from landslide susceptibility to quantitative risk assessment". Landslides 2(4): 321-328, DOI: 10.1007/s10346-005-0016-x. 
Santacana, N., Baeza, B., Corominas, J., Paz, A.D., and Marturiá, J. (2003). "A GIS-Based Multivariate Statistical Analysis for Shallow Landslide Susceptibility Mapping in La Pobla de Lillet Area (Eastern Pyrenees, Spain)". Natural Hazards 30(3): 281-295, DOI: 10.1023/B:NHAZ.0000007169.28860.80.

Sarkar, Sh., Roy, A.K., and Martha, T.R. (2013). "Landslide susceptibility assessment using Information Value Method in parts of the Darjeeling Himalayas". Journal of the Geological Society of India 82(4): 351-362, DOI: 10.1007/s12594-013-0162-z.

Shit, P.K., Bhunia, G.S., and Maiti, R. (2016). "Potential landslide susceptibility mapping using weighted overlay model (WOM)". Modeling Earth Systems and Environment 2: 21, DOI: 10.1007/s40808-016-0078-x.

Shroder, J.F., and Davies, T. (2015). Landslide hazards, risks, and disasters. Hazards and Disasters Series, Elsevier Inc.

Takagi, H. (1997). Introduction to fuzzy systems, neural networks, and genetic algorithms. Intelligent hybrid systems: fuzzy logic, neural networks, and genetic algorithms (Edited by Da Ruan). Springer Science+Business Media, LLC.

Tsangaratos, P., and Benardos, A. (2014). "Estimating landslide susceptibility through a artificial neural network classifier”. Natural Hazards 74(3): 1489-1516, DOI: 10.1007/s11069-014-1245$\mathrm{X}$.

Vu-Bac, N., Lahmer, T., Zhuang, X., Nguyen-Thoi, T., and Rabczuk, T. (2016). "A software framework for probabilistic sensitivity analysis for computationally expensive models". Advances in Engineering Software 100: 19-31, DOI: 10.1016/j.advengsoft.2016.06.005.

Yazdani-Chamzini, A., (2014). "Proposing a new methodology based on fuzzy logic for tunnelling risk assessment". Journal of Civil Engineering and Management 20(1): 82-94, DOI: 10.3846/13923730.2013.843583.

Yazdani-Chamzini, A., Razani, M., Yakhchali, S.H., Zavadskas, E.K., and Turskis, Z. (2013). "Developing a fuzzy model based on subtractive clustering for road header performance prediction". Automation in Construction 35: 111-120, DOI: 10.1016/j.autcon.2013.04.001.

Yen, J., and Wang, L. (1999). "Simplifying fuzzy rule-based models using orthogonal transformation methods". IEEE Transactions on Systems, Man and Cybernetics, Part B (Cybernetics) 1(29): 1324, DOI: $10.1109 / 3477.740162$.

Zadeh, L. A., (1965). "Fuzzy sets". Information and Control 8(3): 338-353, DOI: 10.1016/S00199958(65)90241-X.

Zadeh, L.A., (1996). Fuzzy logic = computing with words. IEEE Transactions on Fuzzy Systems 4 (2): 103-111, DOI: 10.1109/91.493904. 